\title{
Intriguing light-emission features of ketoprofen-based Eu(III) adduct due to a strong electron-phonon coupling
}

\author{
M.G. Lahoud ${ }^{\mathrm{a}, \mathrm{b}}$, R.C.G. Frem ${ }^{\mathrm{a}}$, D.A. Gálico ${ }^{\mathrm{c}}$, G. Bannach ${ }^{\mathrm{c}}$, M.M. Nolasco ${ }^{\mathrm{d}}$, R.A.S. Ferreira ${ }^{\mathrm{b}}$, \\ L.D. Carlos ${ }^{\mathrm{b}, *}$ \\ a Instituto de Química, UNESP - Univ. Estadual Paulista, Campus Araraquara, Departamento de Química Inorgânica, C.P. 355, 14801-970, Brazil \\ ${ }^{\mathrm{b}}$ Department of Physics, CICECO Aveiro Institute of Materials, University of Aveiro, 3810-193 Aveiro, Portugal \\ ${ }^{\mathrm{c}}$ Faculdade de Ciências, UNESP - Univ. Estadual Paulista, Faculdade de Ciências, Campus Bauru, Departamento de Química, C.P. 355, 17033-260, Brazil \\ ${ }^{\mathrm{d}}$ Department of Chemistry and CICECO Aveiro Institute of Materials, University of Aveiro, 3810-193 Aveiro, Portugal
}

\section{A R T I C L E I N F O}

\section{Article history:}

Received 20 February 2015

Received in revised form

30 July 2015

Accepted 25 August 2015

Available online 2 September 2015

Keywords:

Lanthanide coordination compounds

Ketoprofen

Electron-phonon coupling

${ }^{5} \mathrm{D}_{0}$ lifetime dependence with the excitation wavelength

\begin{abstract}
A B S T R A C T
Lanthanide-based coordination compounds of molecular formula $\left[\operatorname{Ln}(\text { keto })_{3}\left(\mathrm{H}_{2} \mathrm{O}\right)\right]$, where $\mathrm{Ln}=\mathrm{Gd}$, Eu and keto=ketoprofen, were synthesized and their photoluminescence features were detailed in the $12-300 \mathrm{~K}$ interval. The emission spectra of $\left[\mathrm{Eu}(\text { keto })_{3}\left(\mathrm{H}_{2} \mathrm{O}\right)\right]$ reveal a strong dependence with the temperature, well-illustrated by an unusual large blue-shift $\left(\sim 17 \mathrm{~cm}^{-1}\right)$ of the ${ }^{5} \mathrm{D}_{0} \rightarrow{ }^{7} \mathrm{~F}_{0}$ transition as the temperature is raised. The arithmetic difference between the absorption spectrum of $\left[\mathrm{Eu}(\mathrm{keto})_{3}\left(\mathrm{H}_{2} \mathrm{O}\right)\right]$ with that of $\left.[\mathrm{Gd} \text { (keto })_{3}\left(\mathrm{H}_{2} \mathrm{O}\right)\right]$ pointed out the presence of a ligand-to-metal charge transfer (LMCT) band (320-370 nm). From the $\left[\mathrm{Gd}(\text { keto })_{3}\left(\mathrm{H}_{2} \mathrm{O}\right)\right]$ phosphorescence the energy of the keto-related triplet states was determined showing a large overlap with the intra- $4 \mathrm{f}^{6}$ levels and a strong electron-phonon coupling. The high-resonance between the LMCT and triplet states and the $\mathrm{Eu}^{3+}$ levels leads to a strong dependence of the ${ }^{5} \mathrm{D}_{0}$ lifetime value, typical of the presence of operative energy transfer processes.
\end{abstract}

(c) 2015 Elsevier B.V. All rights reserved.

\section{Introduction}

The particular $4 \mathrm{f}$ electronic energy level configuration endows the remarkable spectroscopic features of trivalent lanthanide $\left(\mathrm{Ln}^{3+}\right)$ ions, such as photostability, long lifetimes $\left(>10^{-4} \mathrm{~s}\right)$, large Stokes/anti-Stokes shifts ( $>200 \mathrm{~nm}$ ), narrow bandwidth emissions (full width at half-maximum, FWHM $\sim 1 \mathrm{~nm}$ ) lying from the UV to the near-infrared (NIR) spectral regions, high absolute luminescence quantum yields (up to 0.90), and ligand-dependent sensitization [1-6]. All of these features offer excellent prospects for designing new $\mathrm{Ln}^{3+}$-based luminescent materials with a wide range of applications in lighting and displays, integrated optics and optical telecommunications, solar cells, sensors, and biomedicine [7-10].

Lanthanide-sensitized luminescence is a detection technique in clinical analysis that has gained considerable interest due to its high sensitivity and selectivity [11]. For instance, ibuprofen and ketoprofen (keto) analytes were detected in pharmaceutical formulations and mixture of drugs through $\mathrm{Eu}^{3+}$ - and $\mathrm{Tb}^{3+}$-sensitized luminescence [12,13]. Ketoprofen (Fig. 1) is a non-steroidal anti-

\footnotetext{
* Corresponding author.

E-mail address: lcarlos@ua.pt (L.D. Carlos).
}

inflammatory drug with considerable pharmaceutical and commercial interest and whose therapeutic activity is related to the inhibiting effect on selected cyclooxygenase reactions in the biosynthesis of prostaglandins from archidonate [12]. Moreover, in addition to the benzophenone chromophore group that displays a strong absorption in the UV spectral region permitting light harvesting, keto contains a carboxylic acid group, which is known to form complexes with $\mathrm{Ln}^{3+}$ ions (Fig. 1).

The present paper is in line of the work of Refs. [14,15] where some of us synthesized and characterized $\mathrm{Ln}^{3+}$ complexes of ketoprofen motivated by the structural similarity with other $\mathrm{Ln}^{3+}$-based complexes that have pharmacological, diagnostic and therapeutic applications [16-18]. The already reported structural characterization data of those lanthanide complexes (specifically the elemental and thermogravimetry analysis, FT-IR, and X-ray diffraction patterns data-well described in Ref. [14] allowed the establishment of the stoichiometry of the complexes. The $\mathrm{Eu}^{3+}$ complex is in accordance with the molecular formula $\left[\mathrm{Eu}(\text { keto })_{3}\left(\mathrm{H}_{2} \mathrm{O}\right)\right]$ (Fig. 1), providing an uncommon example of a europium complex with coordination number seven, even when small ligands such as carboxylate (in a bidentate form) and water are used. The luminescence features here in evaluated reveal intriguing details due to a strong electron-phonon coupling. 


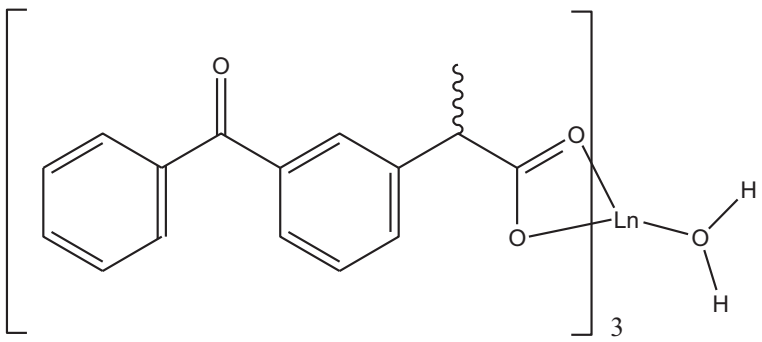

Fig. 1. Chemical structure of $\left[\operatorname{Ln}(\text { keto })_{3}\left(\mathrm{H}_{2} \mathrm{O}\right)\right], \mathrm{Ln}=\mathrm{Eu}, \mathrm{Gd}$.

\section{Materials and methods}

\subsection{Synthesis}

The [ $\left.\mathrm{Ln}(\mathrm{keto})_{3}\left(\mathrm{H}_{2} \mathrm{O}\right)\right], \mathrm{Ln}=\mathrm{Gd}$, Eu, coordination compounds (Fig. 1) were synthesized as described in Ref. [14]. Ketoprofen obtained from Sigma-Aldrich ( $\geq 98 \%$ ) was used without further purification. An aqueous solution of sodium ketoprofen salt was prepared by neutralization the ketoprofen $(0.546 \mathrm{mmol}, 139 \mathrm{mg})$ with solution of sodium hydroxide $\left(1 \mathrm{~mol} \mathrm{~L}^{-1}\right)$ until the $\mathrm{pH}$ to be adjusted to 8.0 . Then, it was slowly added to the respective lanthanide chloride $\left(\mathrm{EuCl}_{3} \cdot 6 \mathrm{H}_{2} \mathrm{O}\right.$ was $0.136 \mathrm{mmol}, 50 \mathrm{mg} ; \mathrm{GdCl}_{3} \cdot 6 \mathrm{H}_{2} \mathrm{O}$ was $0.137 \mathrm{mmol}$, $51 \mathrm{mg}$, Sigma-Aldrich, 99.99\%) with continuous stirring and $\mathrm{pH}$ controlling, until total precipitation of the metal ion. The precipitates were filtered (Whatman no. 42 filter paper), washed with distilled water in order to eliminate chloride ions, dried, and kept in a desiccator over anhydrous calcium chloride. Yield: 85\%. Anal. Calc. for $\mathrm{C}_{48} \mathrm{H}_{41} \mathrm{EuO}_{10}$ : C, 62.00\%; H, 4.44\%; Eu, 16.34\%. Found: C, 61.95\%; H, $4.53 \%, \mathrm{Eu}, 16.00 \%$.

Structural characterization to confirm the suitability of the complexes synthesis was also provided by FT-IR and thermogravimetric analysis and it is in good agreement with the data reported at Ref. [14].

\subsection{Methods}

\subsubsection{Elemental analysis}

Elemental analyses of $\mathrm{C}$ and $\mathrm{H}$ were carried out using a $\mathrm{CE}$ Instruments EA1110 CHNS-O microanalyzer. Europium content was determined by ICP-OES (Inductively Coupled Plasma Optical Emission Spectroscopy) analysis on a Horiba-Jobin Yvon model Activa-M.

\subsubsection{UV/visible absorption}

Diffuse reflectance spectra were recorded at room-temperature, using a dual beam spectrometer Lambda 950 (Perkin-Elmer), with a $150 \times 10^{-3} \mathrm{~m}$ diameter Spectralon ${ }^{\circledR}$ integrating sphere with a spectral resolution of $0.5 \mathrm{~nm}$.

\subsubsection{Photoluminescence}

The emission and excitation spectra were recorded with a modular double grating excitation spectrofluorimeter with a TRIAX 320 emission monochromator (Fluorolog-3, Horiba Scientific) coupled to a photomultiplier (R928, Hamamatsu), using the front face acquisition mode. The excitation source was a $450 \mathrm{~W}$ Xe arc lamp. The emission spectra were corrected for detection and optical spectral response of the spectrofluorimeter and the excitation spectra were corrected for the spectral distribution of the lamp intensity using a photodiode reference detector. The temperature dependent $(12-300 \mathrm{~K})$ photoluminescence measurements were performed using a He closed-cycle cryostat and the temperature was increased using an auto-tuning temperature controller (Lakeshore 331) with a resistance heater with maximum accuracy of $0.1 \mathrm{~K}$. The emission decay curves were acquired with the same spectrofluorimeter using a pulsed Xe-Hg lamp (6 $\mu \mathrm{s}$ pulse at half-width and 20-30 $\mu$ s tail) and a pulsed LED peaking at $560 \mathrm{~nm}$ (SpectraLED-560, Horiba Scientific) coupled to a TBX-04 photomultiplier tube module. The emission spectra of the SpectraLED-560 display a Gaussian profile with a FWHM of $15 \mathrm{~nm}$.

\subsubsection{Absolute emission quantum yields}

The room-temperature emission quantum yields $(q)$ were measured with a C9920-02 system from Hamamatsu with a $150 \mathrm{~W}$ Xe lamp coupled to a monochromator for wavelength discrimination, an integration sphere as the sample chamber and a multichannel analyzer for signal detection. Three measurements were taken for [ $\left.\mathrm{Eu}(\text { keto })_{3}\left(\mathrm{H}_{2} \mathrm{O}\right)\right]$ to provide an average value. The error in the quantum yield values associated with this technique was estimated to be within $10 \%$, according to the manufacturer.

\subsubsection{Theoretical calculations}

Recent investigations have shown that hybrid density functional B3LYP (Becke-Lee-Young-Parr composite of exchange correlation functional) method [19] is reliable for the description of geometrical parameters and electronic structure of $\mathrm{Ln}^{3+}$ complexes [20]. Thus, and considering that $\mathrm{f}$ orbitals do not play a major role in Eu-ligand bonds [21], we use the B3LYP/ECP approach (Effective Core Potential including the $\mathrm{N} 4 \mathrm{f}$ electrons) [22]. With this approach, the $\mathrm{Eu}^{3+}$ ion becomes closed-shell, so the complexes have an even number of electrons leading to a ground-state singlet $\left(\mathrm{S}_{0}\right)$. Therefore, we do not consider the excited states for intra- $4 \mathrm{f}$ transitions in the $\mathrm{Eu}^{3+}$ ion but only the excited states for ligand excitations. Standard 6-31 G basis sets were employed for the $\mathrm{C}$ and $\mathrm{H}$ and $6-31+\mathrm{G}$ for the $\mathrm{O}$ atoms. The molecular structure [Eu(keto $\left.)_{3}\left(\mathrm{H}_{2} \mathrm{O}\right)\right]$ was fully optimized without symmetry restrictions by the gradient procedure. Harmonic vibrational wave numbers were calculated at the same level, using analytical second derivatives, for the optimized geometry, confirming that the matrices of the energy second derivatives (Hessians) have no imaginary eigenvalues (real minima geometries). The vertical electronic excitation energies related with the singlet (S) states were obtained by time-dependent DFT (TD-DFT) calculations with standard 6-31G basis sets employed for the $\mathrm{C}$ and $\mathrm{H}$ and $6-311+\mathrm{G}(\mathrm{d}, \mathrm{p})$ for the $\mathrm{O}$ atoms. All quantum chemistry calculations were performed with Gaussian 03 W-Revision D.02 program package [23] using its default criteria.

\section{Results and discussion}

\subsection{Emission and excitation spectra}

Fig. 2 shows the room-temperature emission spectrum of $\left[\mathrm{Eu}(\text { keto })_{3}\left(\mathrm{H}_{2} \mathrm{O}\right)\right]$ revealing the characteristic intra- $4 \mathrm{f}^{6}$ lines ascribed to the ${ }^{5} \mathrm{D}_{0} \rightarrow{ }^{7} \mathrm{~F}_{0-4}$ transitions, whose energy, FWHM, number and relative intensity of the Stark components are independent of the excitation wavelength in the range $280-465 \mathrm{~nm}$ (the spectrum excited at $370 \mathrm{~nm}$ was chosen as an example). However, at $12 \mathrm{~K}$, despite that for excitation wavelengths above $280 \mathrm{~nm}$ the emission spectra resemble that acquired at $300 \mathrm{~K}$, the $\mathrm{Eu}^{3+}$ transitions relative intensity varies upon excitation at $280 \mathrm{~nm}$. In particular, under such excitation wavelength, there is an increase in the relative intensity of the ${ }^{5} D_{0} \rightarrow{ }^{7} F_{1}$ transition and a decrease of that of the ${ }^{5} \mathrm{D}_{0} \rightarrow{ }^{7} \mathrm{~F}_{4}$ transition, suggesting a large distribution of similar $\mathrm{Eu}^{3+}$-local sites. Analyzing in more detail the high-resolution $12 \mathrm{~K}$ emission spectra, it is observed a single component for the ${ }^{5} \mathrm{D}_{0} \rightarrow{ }^{7} \mathrm{~F}_{0}$ transition (inset in Fig. 2), whose energy $\left(17,248.8 \pm 3.0 \mathrm{~cm}^{-1}\right)$ and FWHM $\left(24.0 \pm 3.0 \mathrm{~cm}^{-1}\right)$ are independent of the excitation wavelength. This indicates that the $\mathrm{Eu}^{3+}$ ions occupy a single average local environment, despite the aforementioned distribution of analogous coordination sites. The 
presence of a single ${ }^{5} \mathrm{D}_{0} \rightarrow{ }^{7} \mathrm{~F}_{0}$ line, the ${ }^{7} \mathrm{~F}_{1,2}$ Stark splitting in 3 and 4 components (marked with arrows in Fig. 2), respectively, points out a low symmetry $\mathrm{Eu}^{3+}$ local site without an inversion center, in accord with the higher relative intensity of the ${ }^{5} \mathrm{D}_{0} \rightarrow{ }^{7} \mathrm{~F}_{2}$ transition (the ${ }^{5} \mathrm{D}_{0} \rightarrow{ }^{7} \mathrm{~F}_{2} /{ }^{5} \mathrm{D}_{0} \rightarrow{ }^{7} \mathrm{~F}_{1}$ intensity ratio is $\sim 4.3$ ).

Whereas [ $\left.\mathrm{Eu}(\text { keto })_{3}\left(\mathrm{H}_{2} \mathrm{O}\right)\right]$ is photostable for visible irradiation, it displays the typical photodegradation of other $\mathrm{Eu}^{3+}$ complexes with $\beta$-diketonate chelates, carboxylic acid derivatives, cryptands, and methaneseleninate ligands under continuous UV irradiation [24], (Fig. S1, Supporting information). To minimize this effect (whose analysis lies outside the scope of the present manuscript) the emission and excitation spectra were measured in nonexposed samples.

Fig. 3A shows the room-temperature excitation spectrum of $\left[\mathrm{Eu}(\text { keto })_{3}\left(\mathrm{H}_{2} \mathrm{O}\right)\right]$ monitored at the ${ }^{5} \mathrm{D}_{0} \rightarrow{ }^{7} \mathrm{~F}_{2}$ maximum. The spectrum is dominated by two components peaking at $\sim 272 \mathrm{~nm}$ and $\sim 360 \mathrm{~nm}$, overlapping a series of intra- $4 \mathrm{f}^{6}$ lines ascribed to transitions between the ${ }^{7} \mathrm{~F}_{0,1}$ levels and the ${ }^{5} \mathrm{~L}_{6}$ and ${ }^{5} \mathrm{D}_{3-1}$ excited states. The diffuse reflectance spectrum (Fig. 3B) also displays a broad absorption in the range $250-400 \mathrm{~nm}$ in which the lowwavelength component, with maximum at $260-270 \mathrm{~nm}$, is ascribed to the keto-ligand singlet states, as demonstrated by TD-DFT calculations.

The calculated singlet-singlet excitations energies were obtained from TD-DFT calculations performed on the B3LYP optimized structure (Fig. 4) and compared to the experimental values extracted from the diffuse reflectance spectrum of $\left[\mathrm{Gd}(\text { keto })_{3}\left(\mathrm{H}_{2} \mathrm{O}\right)\right]$ (Fig. 3B). The calculated absorption maximum at $270 \mathrm{~nm}$ (Fig. 4B) fits very well with the experimental one. As it will be discussed here in after, a

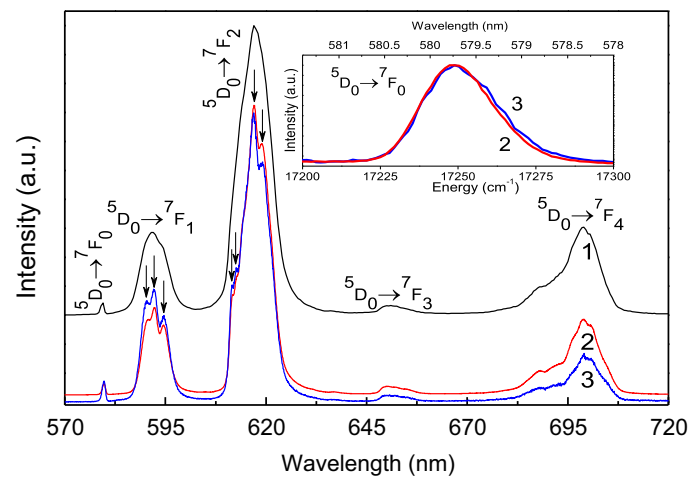

Fig. 2. Emission spectra of $\left[\mathrm{Eu}(\mathrm{keto})_{3}\left(\mathrm{H}_{2} \mathrm{O}\right)\right]$ acquired at (1) $300 \mathrm{~K}$ excited at $370 \mathrm{~nm}$ and at $12 \mathrm{~K}$ excited at (2), $370 \mathrm{~nm}$ and (3) $280 \mathrm{~nm}$; the inset shows a magnification $(\times 20)$ of the ${ }^{5} \mathrm{D}_{0} \rightarrow{ }^{7} \mathrm{~F}_{0}$ transition $(12 \mathrm{~K})$.

A

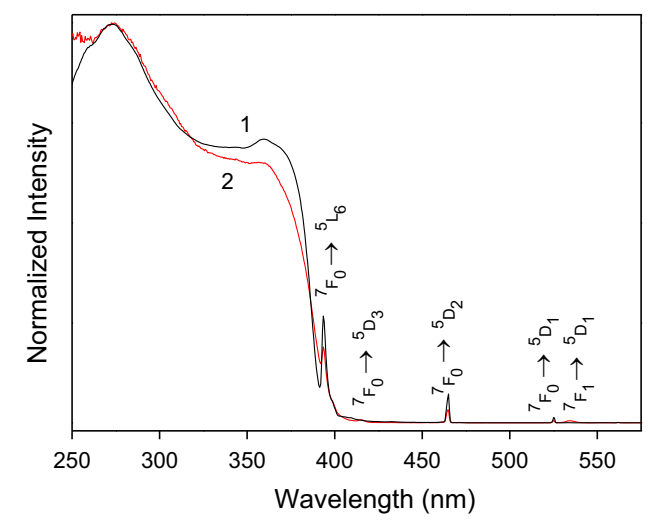

strong electron-phonon coupling is observed in $\left[\mathrm{Eu}(\text { keto })_{3}\left(\mathrm{H}_{2} \mathrm{O}\right)\right]$. Therefore, the comparison between experimental and theoretical triplet energy values is not reasonable, as the TD-DFT calculations cannot predict the excited states for ligand excitations in the presence of electron-phonon coupling.

Aiming at discern in the spectra of Fig. $3 \mathrm{~A}$ the contribution of a possible ligand-to-metal $\left(\mathrm{O}^{2-} \rightarrow \mathrm{Eu}^{3+}\right)$ charge transfer (LMCT) band, the diffuse reflectance spectrum of $\left[\mathrm{Eu}(\text { keto })_{3}\left(\mathrm{H}_{2} \mathrm{O}\right)\right]$ was compared with that of the isostructural $\left[\mathrm{Gd}(\text { keto })_{3}\left(\mathrm{H}_{2} \mathrm{O}\right)\right]$ complex (Fig. 3B). This procedure is based on the fact that the $\mathrm{Gd}^{3+}$ excited levels lie much higher than the typical energy of the ligand triplet states, disabling any LMCT process [24-26]. The arithmetic difference between the two spectra (inset in Fig. 3B) provides experimental evidence for the presence of LMCT states. The highrelative intensity of the ligands broad band compared with that the intra- $4 \mathrm{f}^{6}$ levels indicates that the $\mathrm{Eu}^{3+}$ excited states are mainly sensitized by the ligands rather than by direct excitation.

The emission features were quantified by the measurement of the absolute emission quantum yield, whose values are dependent on the excitation wavelength. In particular, under excitation within the ligands excited states ( $320 \mathrm{~nm}), q=0.32 \pm 0.03$, whereas under direct $\mathrm{Eu}^{3+}$ excitation $\left({ }^{5} \mathrm{D}_{1}, 525 \mathrm{~nm}\right)$ a lower value was measured, $q=0.08 \pm 0.01$.

\subsection{Thermal quenching}

During the total UV exposure time needed for recording the emission between 12 and $300 \mathrm{~K}(\sim 5 \mathrm{~min})$ the $\mathrm{Eu}(\mathrm{keto})_{3}\left(\mathrm{H}_{2} \mathrm{O}\right)$ complex photodegradates around 15\% (Fig. S1,Supporting information). Then, its contribution for the intensity decrease of the ${ }^{5} \mathrm{D}_{0} \rightarrow{ }^{7} \mathrm{~F}_{0-4}$ transitions can be neglected, being its temperature dependence (Fig. 5A) well described by the classical Mott-Seitz model involving two non-radiative recombination channels in competition $[27,28]$. The total transition probability $W$ of an emitting level, with lifetime $\tau$, may be described by

$W=W_{R}+W_{N R}$

or

$W=\frac{1}{\tau(T)}=\frac{1}{\tau_{R}}+\frac{1}{\tau_{N R}}$

where $T$ is the absolute temperature, $W_{R}$ and $W_{N R}$ are the radiative and non-radiative transition probabilities, respectively, $\tau_{R}$ is the radiative lifetime (assumed to be temperature independent and equal to $\tau_{0}=\tau_{R}(T=0 \mathrm{~K})$ ), and $\tau_{N R}$ is the non-radiative lifetime described by an Arrhenius type dependence
B

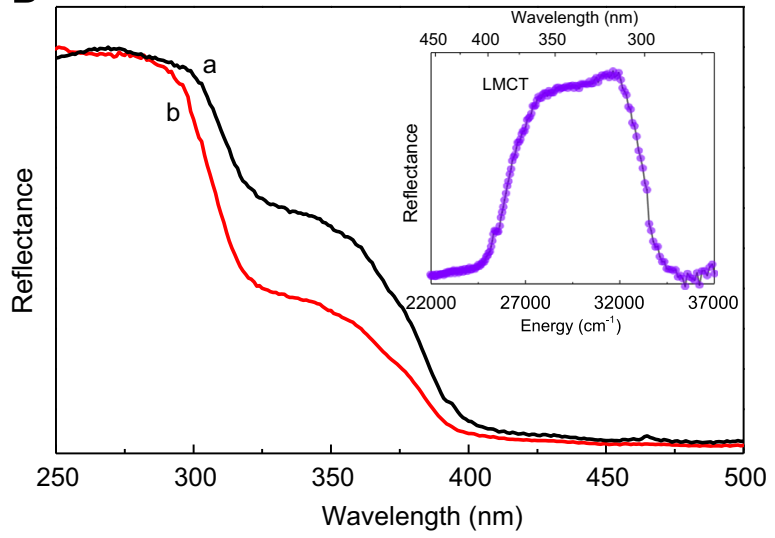

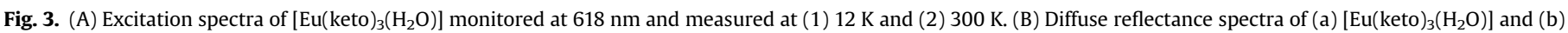
$\left[\mathrm{Gd}(\text { keto })_{3}\left(\mathrm{H}_{2} \mathrm{O}\right)\right]$; the inset shows the arithmetic difference between the two spectra. 
A

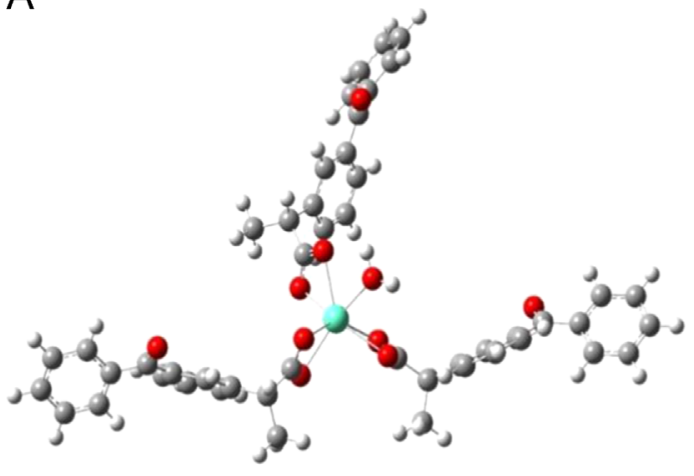

B

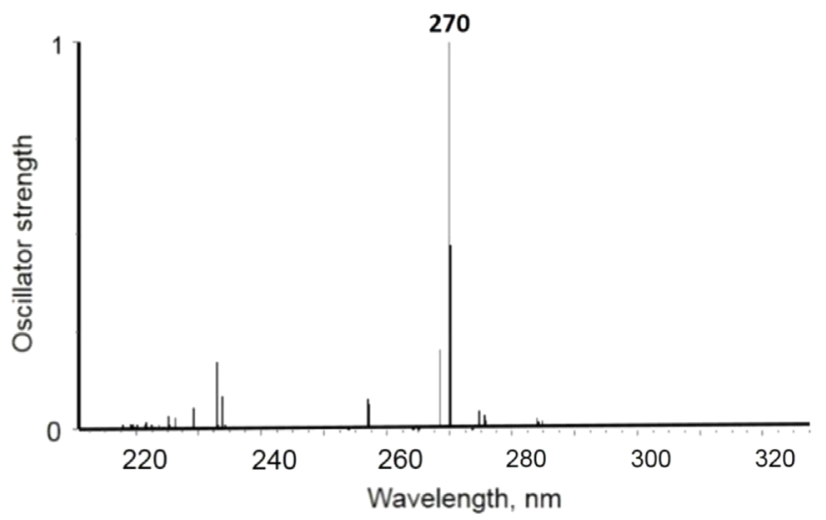

Fig. 4. (A) Optimized molecular geometry obtained from DFT calculations (B3LYP) on [Eu(keto) $\left.)_{3}\left(\mathrm{H}_{2} \mathrm{O}\right)\right]$. (B) Calculated TD-B3LYP transitions depicted as vertical lines.

A

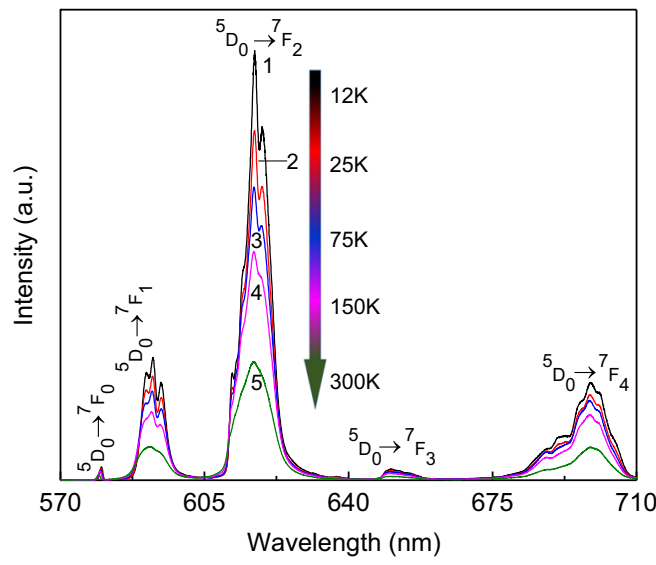

B

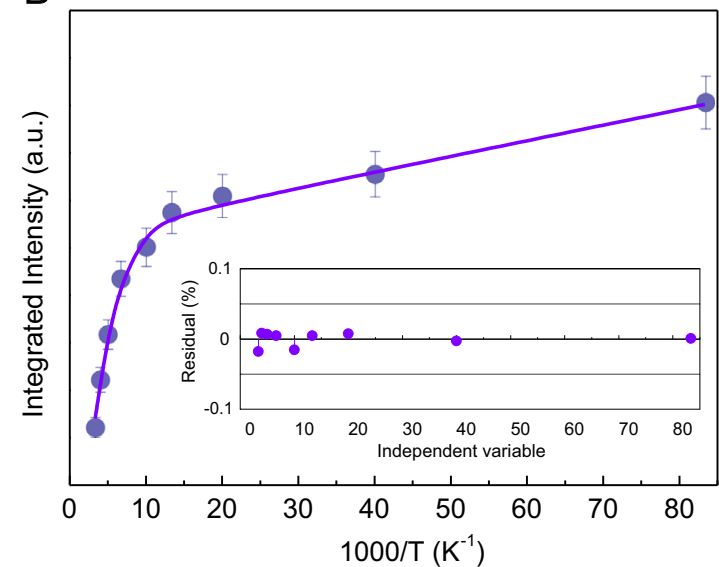

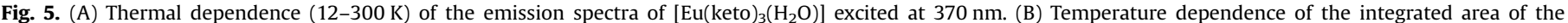
${ }^{5} \mathrm{D}_{0} \rightarrow{ }^{7} \mathrm{~F}_{0-4}$ transitions. The solid line corresponds to the data best fit using Eq. (7) $\left(r^{2}>0.99\right)$. (C) Fit regular residual plot.

$\tau_{N R}=\tau_{N R}(0) \exp \left(-\Delta E / k_{B} T\right)$

with $\Delta E$ the activation energy for the thermal quenching process, $k_{B}$ the Boltzmann constant and $\tau_{N R}(0)$ the non-radiative decay time at $T=0 \mathrm{~K}$. Solving Eq. (2) for the total (experimentally measured) lifetime we can write

$\tau(T)=\frac{\tau_{0}}{1+\alpha \exp \left(-\Delta E / k_{B} T\right)}$

where $\quad \alpha=\tau_{0} / \tau_{N R}(0)=W_{N R}^{0} / W_{R}^{0}$. The integrated luminescence intensity, $I(T)$, may be related with $\tau(T)$ as [29]

$\frac{I(T)}{I_{0}}=\frac{\tau(T)}{\tau_{0}}$

where $I_{0}$ is the integrated intensity at $T=0 \mathrm{~K}$. From Eqs. (4) and (5) it follows

$I(T)=\frac{I_{0}}{1+\alpha \exp \left(-\Delta E / k_{B} T\right)}$.

If the thermal quenching of the ${ }^{5} \mathrm{D}_{0}$ emitting level involves two non-radiative recombination channels in competition, Eq. (6) is written as

$I(T)=\frac{I_{0}}{1+\alpha_{1} \exp \left(-\Delta E_{1} / k_{B} T\right)+\alpha_{2} \exp \left(-\Delta E_{2} / k_{B} T\right)}$

where $I_{0}$ is the integrated intensity of the ${ }^{5} \mathrm{D}_{0} \rightarrow{ }^{7} \mathrm{~F}_{0-4}$ transitions at $T=0 \mathrm{~K}, \alpha_{1}$ and $\alpha_{2}$ are the $\left(W_{N R}^{0}\right)_{i} /\left(W_{R}^{0}\right)_{i}$ ratios for the two processes, and the activation energies $\Delta E_{1}$ and $\Delta E_{2}$ correspond to the energy gap between the ${ }^{5} \mathrm{D}_{0}$ level and the two de-excitation states. Fig. $5 \mathrm{~B}$ shows the data best fit to Eq. (7), that yielded $\Delta E_{1}=494.0 \pm 55.9 \mathrm{~cm}^{-1}$ and $\Delta E_{2}=3.8 \pm 0.6 \mathrm{~cm}^{-1}$ (with $I_{0}=1.72 \pm 0.04 \times 10^{-9} \quad$ arb. units, $\alpha_{1}=36.9 \pm 1.7 \quad$ and $\alpha_{1}=7.2 \pm 0.36$ ). We note that the experimental data is not well described by Eq. (6), in which a single de-excitation state is present (Fig. S2, Supporting information).

To further interpret the two non-radiative paths present in [Eu(keto $\left.)_{3}\left(\mathrm{H}_{2} \mathrm{O}\right)\right]$, a partial energy diagram was drawn, highlighting the overlap between the $\mathrm{Eu}^{3+}$ energy levels and the LMCT and the keto-related excited singlet and triplet states. The energy of the LMCT and keto-ligand singlet states was determined from the $\left.[\mathrm{Eu} \text { (keto })_{3}\left(\mathrm{H}_{2} \mathrm{O}\right)\right]$ and $\left[\mathrm{Gd}(\text { keto })_{3}\left(\mathrm{H}_{2} \mathrm{O}\right)\right]$ reflectance spectra and TD-DFT calculations, respectively. The triplet states energies were inferred from the measurement of the $12 \mathrm{~K}$ time-resolved emission spectrum of $\left[\mathrm{Gd}(\text { keto })_{3}\left(\mathrm{H}_{2} \mathrm{O}\right)\right]$, Fig. 6A. This spectrum resembles that acquired in steady state mode [15], being formed of a broad band with four clearly components, whose energy separation $\left(\Delta E_{v i b} \sim 1550 \mathrm{~cm}^{-1}\right)$ is ascribed to vibrational structure originating from the triplet state of $n \pi^{*}$ emissions of the keto molecule. The zero phonon line (ZPL) energy is $23,255 \pm 20 \mathrm{~cm}^{-1}$. Due to the large spectral range of the triplet states emission, the energy and FWHM $\left(1000 \pm 120 \mathrm{~cm}^{-1}\right)$ of each vibrational component were estimated fitting the emission spectrum to a sum of four Gaussian functions, Fig. 6A. The large overlap between the keto-related triplet levels and the low-energy intra- $4 \mathrm{f}^{6}$ excited states $\left({ }^{5} \mathrm{D}_{0-3}\right)$, indicates that the ligand states thermally depopulate the $\mathrm{Eu}^{3+}$ 
A
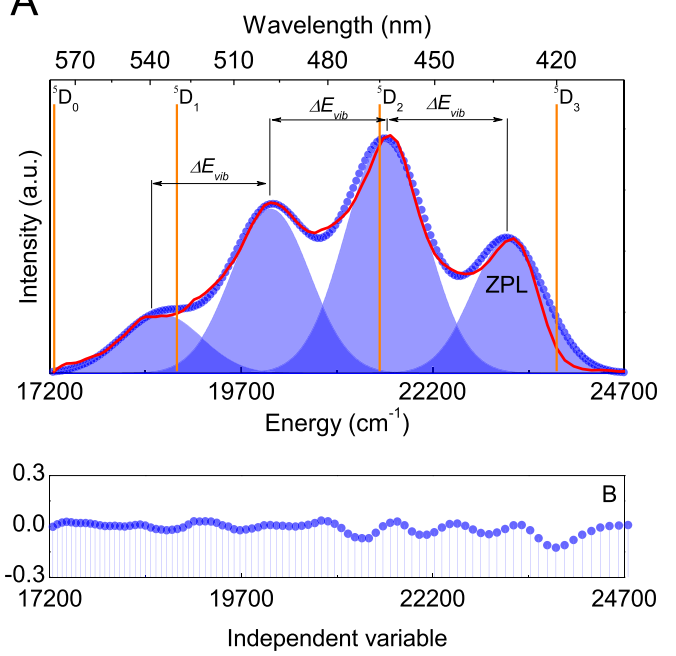

B

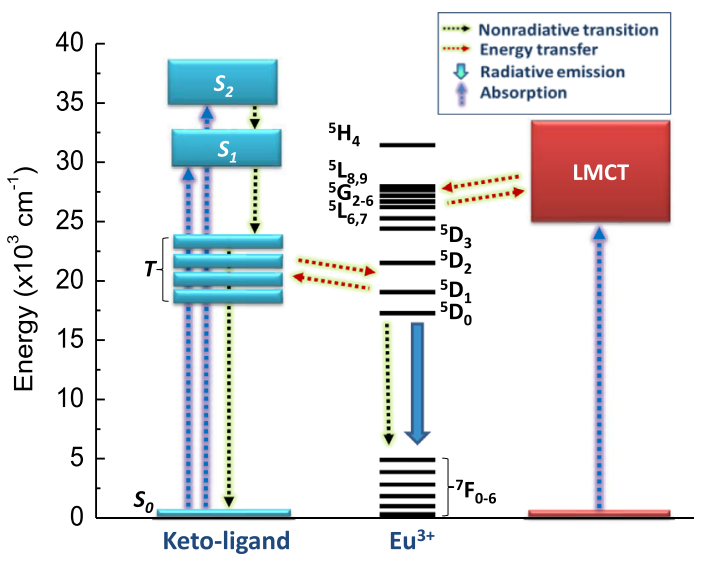

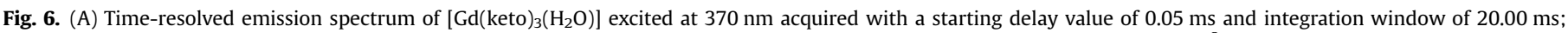

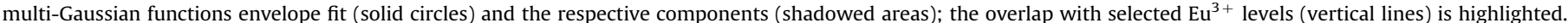

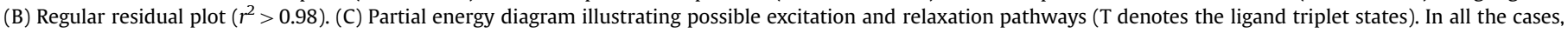
the width of the levels accounts for the FWHM of the bands in the emission and excitation spectra.
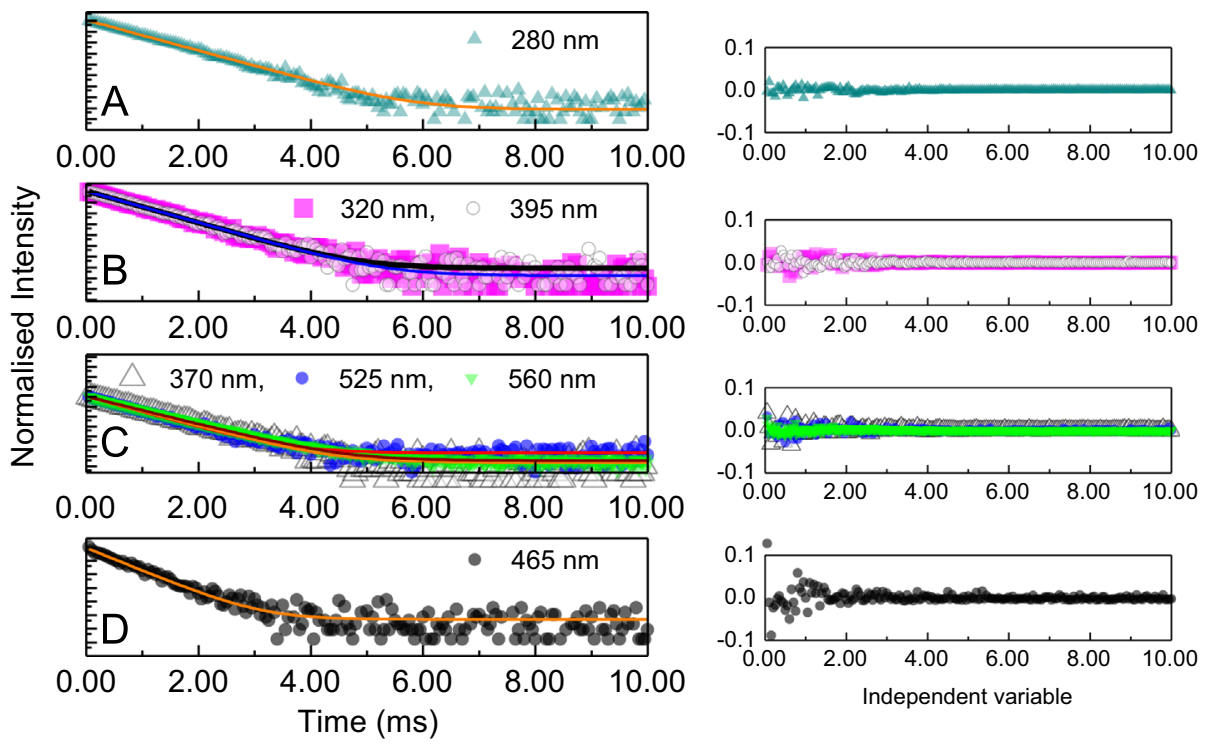

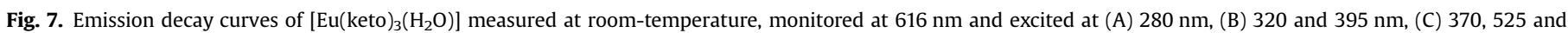
$560 \mathrm{~nm}$ and (D) $465 \mathrm{~nm}$. The solid lines correspond to the data best fit to a single exponential function. Regular residual plots ( $\left.r^{2}>0.99\right)$ are shown on the left.

levels, in agreement with the small $\Delta E$ values estimated from Eq. (7).

\subsection{Decay times}

The time-resolved emission spectrum of [ $\left.\mathrm{Gd}(\text { keto })_{3}\left(\mathrm{H}_{2} \mathrm{O}\right)\right]$ (Fig. $6 \mathrm{~A}$ ) reveals a long-lived emission typical of the triplet state phosphoresce. The respective lifetime was estimated by monitoring the emission decay curve at the zero phonon line (Fig. S3, Supporting information). The curve reveals a non-exponential behavior and an average lifetime value $\langle\tau\rangle$ was calculated from [30]

$\langle\tau\rangle=\frac{\int_{t_{0}}^{t_{1}} I(t) \cdot t \cdot d t}{\int_{t_{0}}^{t_{1}} I(t) \cdot d t}$

where $t_{0}=0.05 \mathrm{~ms}$ and $t_{1}$ is the time value where the luminescence intensity reaches the background, yielding $\langle\tau\rangle=1.2 \pm 0.1 \mathrm{~ms}$.

The ${ }^{5} \mathrm{D}_{0}$ emission decay curves were monitored within the ${ }^{5} \mathrm{D}_{0} \rightarrow{ }^{7} \mathrm{~F}_{2}$ transition (Fig. 7B-E) under distinct excitation paths, namely, LMCT states (320 and $370 \mathrm{~nm}$ ); keto-related triplet (465 and $532 \mathrm{~nm}$ ) and singlet ( $280 \mathrm{~nm}$ ) states, and nearly resonant with the ${ }^{5} \mathrm{D}_{0}$ intra- $4 \mathrm{f}{ }^{6}$ level $(560 \mathrm{~nm})$. All the emission decay curves are well modeled by a single exponential function (in good agreement with the presence of a single average $\mathrm{Eu}^{3+}$ local coordination site), whose fit yielded to ${ }^{5} \mathrm{D}_{0}$ values dependent on the selected excitation wavelength (Fig. 8). Such dependence of the ${ }^{5} \mathrm{D}_{0}$ decay rate on the excitation wavelength is known to occur when energy transfer processes are operative [31]. In particular, in the presence of intermediate states (LMCT and triplet states) in near-resonance with an emitting level mediating energy transfer the lifetime is strongly increased, relative to its intrinsic or natural lifetime [31] (lifetime in the absence of energy transfer processes). We note that 
here the energy diagram of $\left[\mathrm{Eu}(\text { keto })_{3}\left(\mathrm{H}_{2} \mathrm{O}\right)\right]$ is very complicated, due to the presence of low-lying triplet states (unusual in $\mathrm{Eu}^{3+}$-based complexes), and a coupled set of rate equations involving all these states must be build up to model the lifetime dependence with the excitation wavelength and fully understand the system.

The ${ }^{5} \mathrm{D}_{0}$ radiative and nonradiative transition probabilities and the ${ }^{5} D_{0}$ quantum efficiency, defined as

$\eta=\frac{W_{r}}{W_{r}+W_{n r}}$,

were estimated on the basis of the emission spectrum and the ${ }^{5} D_{0}$ lifetime (Eq. (2)), as detailed elsewhere [2]. The $W_{r}$ value was calculated from the relative intensities of the ${ }^{5} \mathrm{D}_{0} \rightarrow{ }^{7} \mathrm{~F}_{0-4}$ transitions (the ${ }^{5} D_{0} \rightarrow{ }^{7} F_{5,6}$ branching ratios were neglected because of their poor relative intensity, relatively to that of the remaining ${ }^{5} \mathrm{D}_{0} \rightarrow{ }^{7} \mathrm{~F}_{0-4}$ lines). The ${ }^{5} \mathrm{D}_{0} \rightarrow{ }^{7} \mathrm{~F}_{1}$ transition does not depend on the local ligand field and thus may be used as a reference for the whole spectrum. An effective refractive index of 1.5 was used leading to $A_{01} \sim 50 \mathrm{~s}^{-1}$ [2], where $A_{01}$ stands for the Einstein's coefficient of spontaneous emission between the ${ }^{5} \mathrm{D}_{0}$ and the ${ }^{7} \mathrm{~F}_{1}$ Stark levels. We stress here the relevance of the excitation wavelength used in the acquisition of the relevant experimental data.

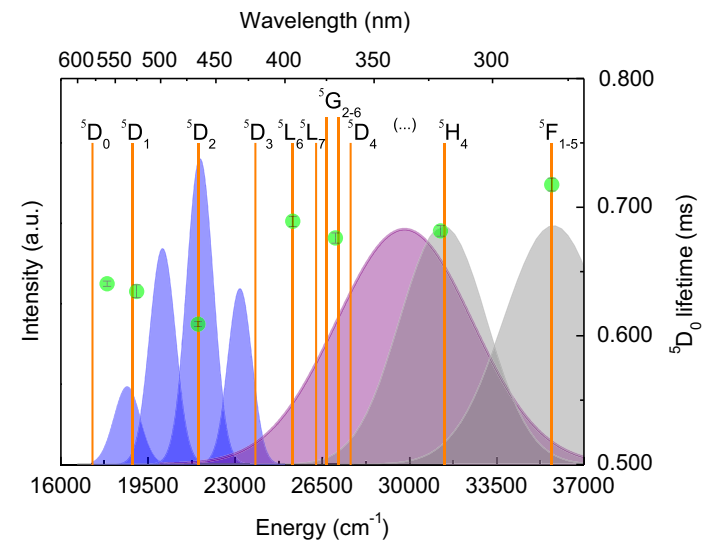

Fig. 8. Scheme illustrating the overlap between the LMCT states (purple Gaussian band), the triplet (blue Gaussian band) and the singlet (gray Gaussian bands) keto states and selected intra- $4 \mathrm{f}^{6}$ levels (vertical lines) for $\left[\mathrm{Eu}(\text { keto })_{3}\left(\mathrm{H}_{2} \mathrm{O}\right)\right]$. The ${ }^{5} \mathrm{D}_{0}$ lifetime values (green circles) measured under distinct excitation wavelengths are also shown. (For interpretation of the references to color in this figure legend, the reader is referred to the web version of this article.)
Attending to the dependence of the ${ }^{5} \mathrm{D}_{0}$ lifetime with the excitation wavelength, the natural (or intrinsic) ${ }^{5} \mathrm{D}_{0}$ lifetime value of $\left.[\mathrm{Eu} \text { (keto })_{3}\left(\mathrm{H}_{2} \mathrm{O}\right)\right]$ is that determined under excitation resonant with the ${ }^{5} D_{0}$ level at $560 \mathrm{~nm}(\tau=0.689 \pm 0.001 \mathrm{~ms})$. This excitation condition avoids the superposition with the LMCT states and minimizes the overlap with the keto-triplet states. In what concerns the $W_{r}$ calculation, the selection of the excitation wavelength to record the emission spectrum is not a critical issue, as for a single average local $\mathrm{Eu}^{3+}$-environment $W_{r}$ is independent of the excitation wavelength. The following values were calculated: $W_{r}=0.299 \mathrm{~ms}^{-1}, W_{n r}=1.152 \mathrm{~ms}^{-1}$ and $\eta=0.21$. The number of water molecules $\left(n_{w}\right)$ in the first coordination sphere was estimated through [32]

$\eta_{w}=1.11\left[\left(\frac{1}{\tau}\right)-W_{r}-0.31\right]$

yielding $n_{w}=0.9 \pm 0.1$, indicating that one water molecule is coordinated to the $\mathrm{Eu}^{3+}$ ions and does not stay outside the coordination sphere, as previously proposed [15]. We note that $\eta$ is larger than the $q$ values measured under ${ }^{5} \mathrm{D}_{1}$ direct excitation, which is in accordance with the definitions of $\eta$ and $q$ that imposes $\eta \geq q$ [2]. We note that if the ${ }^{5} \mathrm{D}_{0}$ lifetime is determined using an excitation wavelength leading to energy transfer processes (through the triplet ligand or the LMCT states), $q$ is no longer defined by Eq. (8).

\subsection{Temperature dependence of the ${ }^{5} D_{0} \rightarrow{ }^{7} F_{0}$ transition}

Another intriguing aspect of the thermal dependence of the [Eu(keto $)_{3}\left(\mathrm{H}_{2} \mathrm{O}\right)$ ] emission is found in the temperature dependence of the ${ }^{5} \mathrm{D}_{0} \rightarrow{ }^{7} \mathrm{~F}_{0}$ transition $(12-300 \mathrm{~K}$, Fig. 9A). Whereas the FWHM shows minor variations within the experimental resolution $\left(\sim 3.0 \mathrm{~cm}^{-1}\right)$, the energy peak, $E_{0}(T)$, reveals an approximately linear blue-shift as the temperature is raised from 25 to $300 \mathrm{~K}$ with a maximum splitting of $\Delta E_{0}=E_{0}(300 \mathrm{~K})-E_{0}(12 \mathrm{~K})=16.6 \pm 3.0 \mathrm{~cm}^{-1}$ (Fig. 9B). A thermal induced blue-shift of the ${ }^{5} \mathrm{D}_{0} \rightarrow{ }^{7} \mathrm{~F}_{0}$ transition was previously reported in other $\mathrm{Ln}^{3+}$-based materials, from which we highlight the examples containing $\mathrm{Eu}^{3+}$ [33-40]. Selected $\Delta E_{0}$ examples are overlapped with the value found for $\left[\mathrm{Eu}(\text { keto })_{3}\left(\mathrm{H}_{2} \mathrm{O}\right)\right]$ in Fig. 9B. We note, that the ${ }^{5} \mathrm{D}_{0} \rightarrow{ }^{7} \mathrm{~F}_{0}$ energy dependence was also studied above room-temperature for $\mathrm{Eu}^{3+}$-based oxides, revealing also a blue-shift $\left(16.50 \mathrm{~cm}^{-1}\right)$ as the temperature is raised up to $648 \mathrm{~K}$ [37].
A

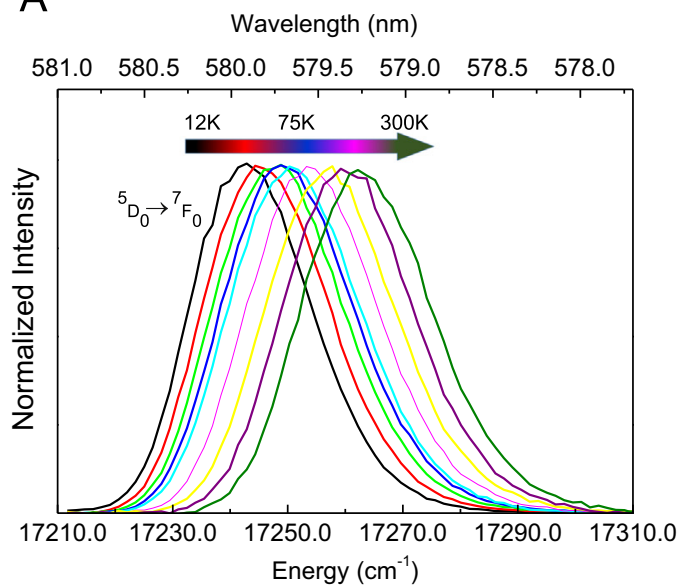

B

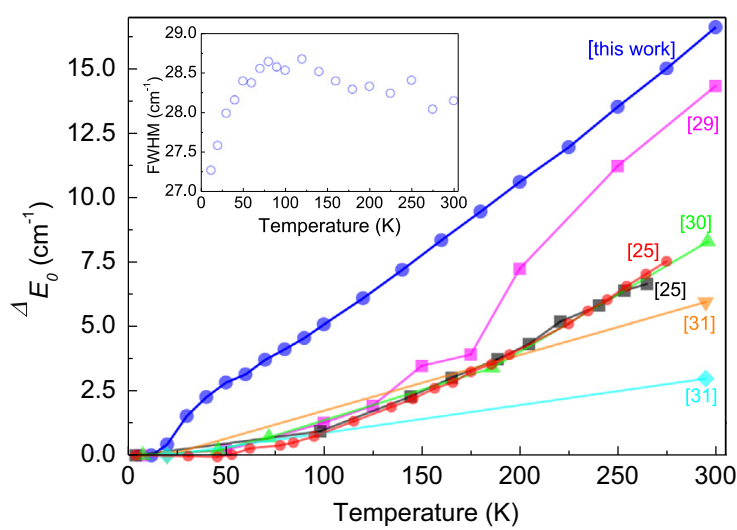

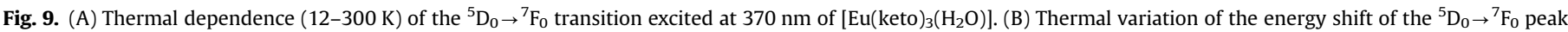

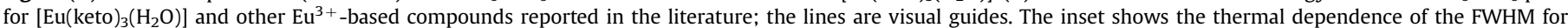
$\left[\mathrm{Eu}(\text { keto })_{3}\left(\mathrm{H}_{2} \mathrm{O}\right)\right]$. 
The ${ }^{5} D_{0} \rightarrow{ }^{7} F_{0}$ temperature dependence is determined by the interaction between the f electrons, which is mediated by two mechanisms: (i) electron-phonon coupling (dynamic interaction) and (ii) thermal expansion of the host affecting the crystal field (static interaction) $[33,41]$. The relative contribution of each mechanism is not easily determined, namely, through direct measurements. Nevertheless, there are experimental evidences that allow the identification of the most probable mechanism for the observed thermal dependence of the energy of the ${ }^{5} \mathrm{D}_{0} \rightarrow{ }^{7} \mathrm{~F}_{0}$ transition. In particular, the linear relation found between $\Delta E_{0}$ and the crystal internal energy in several hydrated $\mathrm{Eu}^{3+}$-based complexes provided experimental evidence supporting that electronphonon coupling mediated by acoustic phonons is the main contribution [33], which is also the case observed for the $\left[\mathrm{Eu}(\mathrm{keto})_{3}\left(\mathrm{H}_{2} \mathrm{O}\right)\right]$, Fig. 9B. Moreover, we also stress the strong electron-phonon coupling which certainly plays a relevant mechanism in the larger average shift $\Delta E_{0}$. We note that although the FWHM dependence on the temperature lies within the experimental resolution $\left(3 \mathrm{~cm}^{-1}\right)$, it is observed a broadening in the temperature region below $50 \mathrm{~K}$, which supports the presence of quite strong electron-phonon coupling [33]. Further work is undergoing, in order to detail the mechanism behind the thermal induced blue-shift of the ${ }^{5} \mathrm{D}_{0} \rightarrow{ }^{7} \mathrm{~F}_{0}$ transition observed for $\left[\mathrm{Eu}(\text { keto })_{3}\left(\mathrm{H}_{2} \mathrm{O}\right)\right]$.

\section{Conclusions}

In this work, the photoluminescence features of the $\left[\mathrm{Eu}(\text { keto })_{3}\left(\mathrm{H}_{2} \mathrm{O}\right)\right]$ coordination compound are discussed in detail. The corresponding $\mathrm{Eu}^{3+}$ energy diagram reveals complicated energy transfer mechanisms involving the large overlap between the LMCT states (320-370 nm) and the keto-related triplet states (400-570 nm) with the $\mathrm{Eu}^{3+}$ levels. This overlap yields to a strong dependence of the ${ }^{5} \mathrm{D}_{0}$ lifetime on the excitation wavelength. Moreover, the large overlap between the ligands states and the $\mathrm{Eu}^{3+}$ levels results in a strong electron-phonon coupling which may account for the intriguing thermal dependence of the emission spectra. In particular, a significant blue-shift $\left(\sim 17 \mathrm{~cm}^{-1}\right)$ of the ${ }^{5} \mathrm{D}_{0} \rightarrow{ }^{7} \mathrm{~F}_{0}$ peak as the temperature is raised from 12 to $300 \mathrm{~K}$ is measured. This thermal dependence may envisage future developments of $\left[\mathrm{Eu}(\text { keto })_{3}\left(\mathrm{H}_{2} \mathrm{O}\right)\right]$ in the field of molecular thermometry.

\section{Acknowledgments}

This work is partially developed in the scope of the project CICECO-Aveiro Institute of Materials (Ref. FCT UID/CTM/5001/ 2013), financed by Portuguese funds through FCT/MEC and when applicable co-financed by FEDER under the PT2020 Partnership Agreement. M.M.N. (BPD/UI96/3340/2014) also acknowledge the post-doctoral scholarship under the Project Mais Centro - PORC, CENTRO-07-ST24-FEDER-002032. CAPES and CNPq foundations (Brazil) are also acknowledged for their general funding scheme.

\section{Appendix A. Supplementary material}

Supplementary data associated with this article can be found in the online version at http://dx.doi.org/1016/j.jlumin.2015.08.050.

\section{References}

[1] G.F. de Sá, O.L. Malta, C. de Mello Donegá, A.M. Simas, R.L. Longo, P.A. SantaCruz, E.F. da Silva, Coord. Chem. Rev. 196 (2000) 165.

[2] L.D. Carlos, R.A.S. Ferreira, V. de Zea Bermudez, S.J.L. Ribeiro, Adv. Mater. 21 (2009) 509.

[3] J.-C.G. Bünzli, Chem. Rev. 110 (2010) 2729.

[4] L. Armelao, S. Quici, F. Barigelletti, G. Accorsi, G. Bottaro, M. Cavazzini, E. Tondello, Coord. Chem. Rev. 254 (2010) 487.

[5] J.C.G. Bünzli, S.V. Eliseeva, Chem. Sci. 4 (2013) 1939.

[6] L.D. Sun, Y.F. Wang, C.H. Yan, Acc. Chem. Res. 47 (2014) 1001.

[7] X. Huang, S. Han, W. Huang, X. Liu, Chem. Soc. Rev. 42 (2013) 173.

[8] G.Y. Chen, C.H. Yang, P.N. Prasad, Acc. Chem. Res. 46 (2013) 1474.

[9] S.L. Gai, C.X. Li, P.P. Yang, J. Lin, Chem. Rev. 114 (2014) 2343.

[10] C.D.S. Brites, P.P. Lima, N.J.O. Silva, A. Millán, V.S. Amaral, F. Palacio, L.D. Carlos, Adv. Mater. 22 (2010) 4499.

[11] A. Ruiz-Medina, E.J. Llorent-Martinez, P. Ortega-Barrales, M.L.F.D. Cordova, Appl. Spectrosc. Rev. 46 (2011) 561.

[12] M. Kaczmarek, S. Lis, Anal. Methods 4 (2012) 1964.

[13] S.M.Z. Al-Kindy, Z. Al-Harasi, F.E.O. Suliman, A. Al-Hamadi, A. Pillay, J. Fluoresc. 19 (2009) 249.

[14] D.A. Gálico, B.B. Holanda, G.L. Perpetuo, E. Schnitzler, O. Treu, G. Bannach, J. Therm. Anal. Calorim. 108 (2012) 371.

[15] D.A. Gálico, M.G. Lahoud, M.R. Davolos, R.C.G. Frem, T.F.C. Fraga-Silva, J. Venturini, M.S.P. Arruda, G. Bannach, J. Inorg. Biochem. 140 (2014) 160.

[16] X.J. Zhou, X.Q. Zhao, Y.J. Wang, B. Wu, J. Shen, L. Li, Q.X. Li, Inorg. Chem. 53 (2014) 12275.

[17] Y. Mawani, J.F. Cawthray, S. Chang, K. Sachs-Barrable, D.M. Weekes, K.M. Wasan, C. Orvig, Dalton Trans. 42 (2013) 5999.

[18] W.L. Kwong, R.W.Y. Sun, C.N. Lok, F.M. Siu, S.Y. Wong, K.H. Low, C.M. Che, Chem. Sci. 4 (2013) 747.

[19] A.D. Becke, J. Chem. Phys. 98 (1993) 5648.

[20] M.M. Nolasco, P.M. Vaz, V.T. Freitas, P.P. Lima, P.S. André, R.A.S. Ferreira, P.D. Vaz, P. Ribeiro-Claro, L.D. Carlos, J. Mater. Chem. A 1 (2013) 7339.

[21] L. Maron, O. Eisenstein, J. Phys. Chem. A 104 (2000) 7140.

[22] X.Y. Cao, M. Dolg, Theochem - J. Mol. Struct. 581 (2002) 139.

[23] M.J. Frisch, G.W. Trucks, H.B. Schlegel, G.E. Scuseria, M.A. Robb, J.R. Cheeseman, G. Scalmani, V. Barone, B. Mennucci, G.A. Petersson, H. Nakatsuji, M. Caricato, X. Li, H.P. Hratchian, A.F. Izmaylov, J. Bloino, G. Zheng, J.L. Sonnenberg, M. Had, D.J. Fox, Gaussian, Inc., in, Wallingford CT (2009).

[24] P.P. Lima, M.M. Nolasco, F.A.A. Paz, R.A.S. Ferreira, R.L. Longo, O.L. Malta, L.D. Carlos, Chem. Mater. 25 (2013) 586.

[25] P.P. Lima, F.A.A. Paz, R.A.S. Ferreira, V. de Zea Bermudez, L.D. Carlos, Chem. Mater. 21 (2009) 5099.

[26] L.D. Carlos, J.A. Fernandes, R.A.S. Ferreira, O.L. Malta, I.S. Gonçalves, P. RibeiroClaro, Chem. Phys. Lett. 413 (2005) 22.

[27] N.F. Mott, Proc. R. Soc. 167 (1938) 0384.

[28] F. Seitz, Trans. Faraday Soc. 35 (1939) 0074.

[29] M. Stalder, M. Bass, B.H.T. Chai, J. Opt. Soc. Am. B 9 (1992) 2271.

[30] W.M. Yen, S. Shionoya (Eds.), Phosphor Handbook, CRC Press, Boca Raton, 1999, pp. 712-713.

[31] R.A.S. Ferreira, M. Nolasco, A.C. Roma, R.L. Longo, O.L. Malta, L.D. Carlos, Chem. Eur. J. 18 (2012) 12130.

[32] R.M. Supkowski, W.D. Horrocks Jr., Inorg. Chim. Acta 340 (2002) 44.

[33] P. Hill, S. Hufner, Z. Phys. 240 (1970) 168.

[34] H. Kusama, O.J. Sovers, T. Yoshioka, Jpn. J. Appl. Phys. 15 (1976) 2349.

[35] M. Albin, W.D. Horrocks, Inorg. Chem. 24 (1985) 895.

[36] J. Dexpert-Ghys, J. Halwani, B. Piriou, Inorg. Chim. Acta 139 (1987) 303.

[37] G. Chen, R.G. Haire, J.R. Peterson, J. Solid State Chem. 102 (1993) 126.

[38] S. Taboada, A. de Andres, J.E. Munoz-Santiuste, J. Phys. Condens. Matter 10 (1998) 8983.

[39] J.C. Boyer, F. Vetrone, J.A. Capobianco, A. Speghini, M. Bettinelli, J. Phys. Chem. B 108 (2004) 20137.

[40] K.H. Jang, N.M. Khaidukov, V.P. Tuyen, S.I. Kim, Y.M. Yu, H.J. Seo, J. Alloy. Compd. 536 (2012) 47.

[41] D.E. Mccumber, M.D. Sturge, J. Appl. Phys. 34 (1963) 1682. 